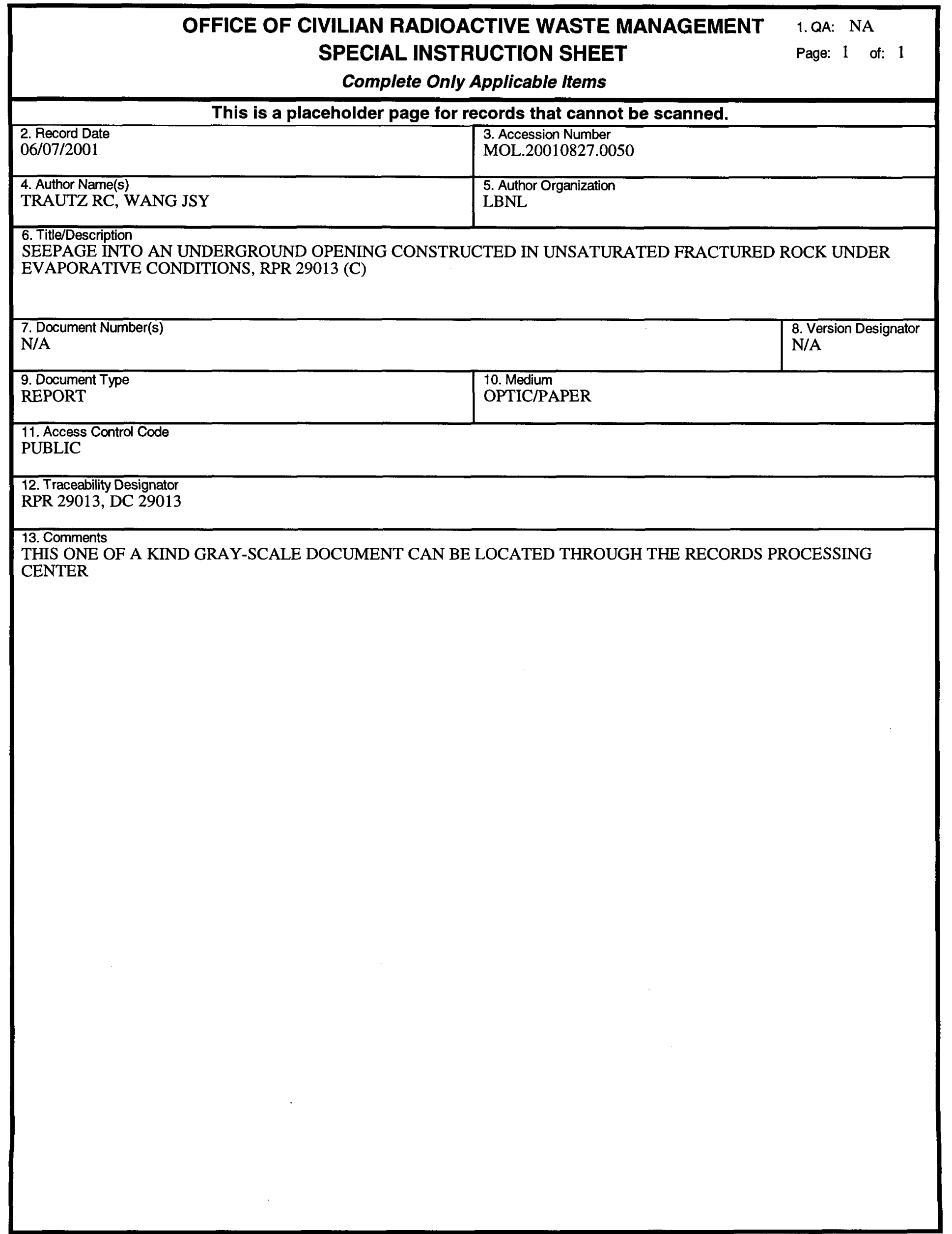




$$
\begin{aligned}
& \text { DC\#29013 } \\
& \text { O6/07101 } \\
& \text { QA:NA }
\end{aligned}
$$

\title{
Seepage into an underground opening constructed in unsaturated fractured rock under evaporative conditions
}

Robert C. Trautz

MOL. 20010827.0050

Earth Sciences Division, Lawrence Berkeley National Laboratory, Berkeley, California

Joseph S. Y. Wang

Earth Sciences Division, Lawrence Berkeley National Laboratory, Berkeley, California

\begin{abstract}
Liquid-release tests, performed in boreholes above an underground opening constructed in unsaturated fractured rock, are used in this study to evaluate seepage into a waste emplacement drift. Evidence for the existence of a capillary barrier at the ceiling of the drift is presented, based on field observations (including spreading of the wetting front across the ceiling and water movement up fractures exposed in the ceiling before seepage begins). The capillary barrier mechanism has the potential to divert water around the opening, resulting in no seepage when the percolation flux is at or below the seepage threshold flux. Liquid-release tests are used to demonstrate that a seepage threshold exists and to measure the magnitude of the seepage threshold flux for three test zones that seeped. The seepage data are interpreted using analytical techniques to estimate the test-specific strength of the rock capillary forces $\left(\alpha^{-1}\right)$ that prevent water from seeping into the drift. Evaporation increases the seepage threshold flux making it more difficult for water to seep into the drift and producing artificially inflated $\alpha^{-1}$ values. With adjustments for evaporation, the minimum test-specific threshold is $1,600 \mathrm{~mm} / \mathrm{yr}$ with a corresponding $\alpha^{-1}$ of $0.027 \mathrm{~m}$.
\end{abstract}

\section{Introduction}

Yucca Mountain, located approximately $160 \mathrm{~km}$ northwest of Las Vegas, Nevada, is being evaluated by the U.S. Department of Energy (DOE) as a potential repository site for the safe disposal of spent nuclear fuel and high-level radioactive waste [DOE, 1998]. If licensed, the repository would be constructed within the mountain, which consists of a thick sequence of rhyolitic ash-flow tuffs exhibiting various degrees of welding, vitrification, fracturing, and abundance of lithophysae cavities. These features influence the mechanical and hydrogeologic properties of the host rock [Buesch et al., 1996; Buesch and Spengler, 1998; Flint, 1998]. Containers of radioactive waste would be placed in underground openings called drifts constructed approximately $300 \mathrm{~m}$ deep in the unsaturated tuff and at least $200-\mathrm{m}$ above the regional water table. 
Yucca Mountain is located in an arid region of the Basin and Range Province. The low annual precipitation rate, thick sequence of overlying unsaturated tuffs, deep regional water table, and the site's remote location are several positive site attributes. Natural barriers to fluid flow and contaminant transport will be relied upon and augmented, using engineered barriers to demonstrate the site's ability to isolate the waste $[D O E, 1998]$. An extensive site characterization effort is underway to evaluate numerous factors influencing repository performance-including the focus of this paper, water movement around and seepage (defined here as water dripping) into a drift under ambient conditions.

A key question concerning potential repository performance is whether precipitation entering the mountain now, and under wetter climate scenarios in the future, will percolate through the deep unsaturated zone to the repository horizon, where it may seep directly into a drift or because of a capillary barrier move around the drift. A capillary barrier is present at the drift ceiling because relatively strong capillary forces in the overlying rock matrix and fractures hold the water in the formation, preventing it from dripping into the drift. Water percolating down through the unsaturated zone from above will be retarded at the capillary barrier, causing both the rock saturation and the water potential (i.e., negative pressure head) to increase in the immediate vicinity of the drift wall. The local increase in water potential creates a lateral component to the hydraulic gradient that drives water around the opening, assuming sufficient lateral permeability and wall surface transmissivity exist to divert the flux.

We performed a series of liquid-release tests in boreholes located above a specially constructed drift, called a niche, to determine whether a capillary barrier is present, to study seepage processes, and to produce a data set for estimating test-specific formation parameters. Air-injection tests and liquid-release tests were conducted before excavating the niche to 
characterize the flow of air and water through relatively undisturbed fractures, and after excavation to quantify water seeping into the niche from liquid releases of known duration and intensity. For each test interval, the seepage threshold flux $\left(\mathrm{K}_{\infty^{*}}\right)$ was determined by a series of liquid releases with progressively lower rates until water no longer seeped into the niche. The seepage data are used to estimate the capillary strength of in situ fractures $\left(\alpha^{-1}\right)$. In addition, field evidence is provided to show that a capillary barrier is present at the niche ceiling, causing water to move laterally around the niche.

It is important to note that the capillary strength of the fractures and seepage threshold fluxes estimated using our approach are specific to the conditions and scale of the seepage experiments, the model used to analyze the data, and the manner in which we define the liquid-release flux.

\section{Capillary Barriers}

Considerable effort has been dedicated to evaluating capillary barriers that occur at the contact between a coarse-grained material and overlying fine-grained material. The primary thrust of these efforts has been the evaluation of sloping capillary barriers and their effectiveness in promoting lateral movement of water downdip along a hydrogeologic contact [Montazer and Wilson, 1984]. A layered capillary barrier's capacity to funnel water away from a desired area has been the impetus for numerous analytical and numerical studies related to waste isolation and optimum landfill cover design [Gardner and Hsieh, 1959; Ross, 1990; Steenhuis et al., 1991; Oldenburg and Pruess, 1993; Stormont, 1995; Webb, 1997; Ho and Webb, 1998; and Selker, 1997]. However, very few detailed laboratory investigations [Miyazaki, 1988; Conca et al., 1998; and Walter et al., 2000] or field studies [Wang et al., 1999] pertaining to capillary barriers have been performed and reported in the literature. 
Or and Ghezzehei [1999] and Ho [1997] studied the effect of evaporation on droplet formation and dripping rates from single fractures terminating at subaterranean cavities. Or and Ghezzehei [1999] concluded that dripping is sensitive to the ambient water vapor pressure in an open cavity and is likely to occur only under very high vapor pressures close to saturation.

Philip et al. [1989a, 1989b], Knight et al. [1989] and Philip [1989a, 1989b, 1990, 1998] were the first to address the capillary barrier problem as it directly relates to seepage into buried cavities. They developed several steady-state analytical solutions for various-shaped cavities buried in a homogeneous unsaturated porous medium and subject to a uniform, constantdownward percolation flux $\left(\mathrm{K}_{\infty}\right)$. When $\mathrm{K}_{\infty}$ exceeds the seepage threshold $\mathrm{K}_{\infty}$, the rock adjacent to the crown of the cavity becomes saturated, producing a zero water potential at the tunnel-rock interface. Under these conditions, the capillary barrier begins to break down, allowing water to drip into the drift and potentially induce waste migration.

The analytical solutions provide insight into the dependency of $\mathrm{K}_{\infty^{*}}$ on the cavity shape and size as well as the capillary strength $\left(\alpha^{-1}\right)$ of the surrounding porous medium. The capillary strength $\alpha^{-1}$ is a parameter characteristic of the unsaturated medium first used by Gardner [1958; see also White and Sully, 1987, and Philip, 1989c] in the exponential approximation of the relation between unsaturated hydraulic conductivity $(\mathrm{K}(\psi))$ and matric potential $(\psi)$. Philip et al.'s [1989a] solution for a circular cylindrical cavity, which is similar in shape to a waste emplacement drift, can be used to show that $\mathrm{K}_{\infty^{*}}$ is smaller for large-diameter drifts compared to small-diameter drifts, assuming the same formation capillary strength. Likewise, $\mathrm{K}_{\infty} *$ is smaller for formations having weak capillary strength (i.e., small $\alpha^{-1}$ ) compared to those exhibiting strong capillarity, assuming the same drift size. This implies that seepage will occur into large 
openings or from rocks exhibiting weak capillarity over a wider range of percolation fluxes than those having smaller diameter or exhibiting stronger capillarity, respectively.

Philip et al. [1989b] found that cavities having parabolic or paraboloidal geometries are the most efficient in their ability to shed water and enhance the effectiveness of the capillary barrier. Although somewhat impractical to construct, parabolic and paraboloidal cavities exhibit the unique characteristic that water potential at the cavity wall is contant, independent of position. For these geometries, the wall of the cavity acts both as a streamline and equipotential surface, excluding or partially admitting seepage uniformly along its entire length depending upon whether $\mathrm{K}_{\infty}$ is less than or greater than $\mathrm{K}_{\infty^{*}}$, respectively. In contrast, the maximum water potential occurs at the apex or crown of a circular cylindrical drift and decreases monotonically along the sidewalls [Philip et al., 1989a]. The maximum water potential at the crown of the drift results in focused seepage along the top and centerline of a cylindrical tunnel.

Hughson and Dodge [2000] extended the work of Philip et al. [1989a] to include cylindrical drifts with undulating (i.e., wavy) surfaces having prescribed periodicity and amplitude. The undulations represent irregularities in the drift walls and ceiling that occur during the mining operation when unsupported blocks of rock shift or drop from the ceiling, producing protruding lobes of rock or voids. Roof or wall collapse may also produce an irregular tunnel surface. Hughson and Dodge [2000] show that under certain surface-roughness conditions, water may accumulate at low points at roof lobes or along asperities in the ceiling. From there, it may seep into the opening at lower percolation fluxes than would be predicted for a smooth-walled cavity.

Recent studies of seepage into underground openings have employed numerical models to investigate the effect of heterogeneous permeability fields typical of fractured rocks and discrete fracturing on seepage rates. Birkholzer et al. [1999] used a dual continuum three-dimensional 
model to study the heterogeneous steady-state flow field around a drift. The study used a variety of present and future climate scenarios expected at Yucca Mountain, realistic cylindrical drift geometry and site-specific formation parameters. For conditions at Yucca Mountain, heterogeneity of the flow domain was the most important factor determining whether seepage will occur. A heterogeneous permeability field leads to focused flow in the high permeability fractures, resulting in local ponding and seepage typically near the crown of the drift. Seepage into the drift occurs at percolation fluxes below the seepage threshold flux predicted using models with a homogeneous permeability field.

Finsterle [2000] incorporated discrete permeability features representative of fractures in a high-resolution continuum model to evaluate the appropriateness of using a continuum approach for the seepage problem. The high-resolution model was used to generate two synthetic seepage data sets showing discrete flow effects. The first data set was used to calibrate a simplified fracture continuum model, exhibiting few if any discrete features. In addition, the fracture continuum model was conditioned using minimal information including: (1) air permeability estimates, (2) assumed variance and isotropic correlation structure of the permeability field, and (3) cumulative seepage data from three sequential synthetic liquid-release tests performed above the drift using the high-resolution model. No fracture density, orientation, aperture distribution, or discrete hydrologic property data were utilized in the calibration. The ability of the calibrated fracture continuum model to predict seepage was then tested by comparing it to the second synthetic data set, which was significantly different than that used in the calibration. The seepage predictions were found to be in good agreement with the synthetic data. Finsterle [2000] to concluded that seepage into an underground opening located in a highly fractured formation can 
be predicted using a fracture continuum model, provided seepage-relevant data are available to calibrate the model.

\section{Site Selection and Description}

The site was selected for our study based on fracture and hydrogeologic data collected in the Main Drift of the Exploratory Studies Facility (ESF). The ESF is a $7.8 \mathrm{~km}$ long, $7.6 \mathrm{~m}$ diameter tunnel excavated into the eastern flank of Yucca Mountain to gain access to the subsurface for exploration and testing at the proposed depth of the potential repository [DOE, 1998]. The site is located within the Topopah Spring Tuff (Tpt) middle nonlithophysal zone (Tptpmn). Beusch and Spengler [1998] indicate that the Tpt is a single cooling unit that formed about 12.8 Ma when a thick pyroclastic flow erupted from its volcanic source. Maximum compaction occurred near the stratigraphic center of the flow producing the Tptpmn, a densely welded, highly fractured, devitrified zone containing few lithophysal cavities. Approximately $20 \%$ of the potential repository would be constructed in the Tptpmn. The geometric-mean fracture conductivity of the Tptpmn derived using in situ air-injection tests is equal to $1.0 \mathrm{E}-06 \mathrm{~m} / \mathrm{s}$ [Cook, 2000]. In comparison, the saturated hydraulic conductivity of the rock matrix measured on rock cores in the laboratory $[$ Flint, 1998$]$ is nearly five orders of magnitude less $(4.0 \mathrm{E}-11 \mathrm{~m} / \mathrm{s})$.

The site is located in a $950 \mathrm{~m}$ long exposure of the Tptpmn referred to by Buesch and Spengler [1998] as the intensely fractured zone. Fractures in this zone are not uniformly spaced but instead occur in clusters that contain closely spaced fractures $(0.23 \mathrm{~m}$ average spacing within clusters). High-angle fractures predominate in the Tptpmn and are related to the initial cooling and compaction of the welded tuff. 


\section{Overview of Test Activities}

\subsection{Pre-Excavation Tests}

Horizontal boreholes were drilled at the locations shown in Figure 1 to a depth of 10 to $12 \mathrm{~m}$ to gain access to the rock for testing purposes before excavating a short drift, called a niche. Three of the borings, designated UL, UM, and UR (upper left, upper middle, and upper right) were installed approximately one meter apart (in the same horizontal plane) and 0.56 to $0.71 \mathrm{~m}$ above the proposed ceiling of the niche. The remaining boreholes (ML, MR, B1.5 and B2.5) were intentionally drilled within the limits of the proposed niche and were subsequently removed when the niche was excavated or were unintentionally damaged during niche construction. All of the boreholes were oriented parallel to the axes of the niche.

Over 100 air-injection tests were conducted in the boreholes prior to niche construction. Cook [2000] analyzed the test data and determined that the geometric-mean air permeability of the fractures at the niche site is $1.3 \mathrm{E}-13 \mathrm{~m}^{2}$. The air injection tests were used to select test intervals for subsequent liquid-release tests described below.

A series of pre-excavation liquid-release tests. were conducted at the niche by pumping approximately 1.0 liter of water containing colored or fluorescent dyes at a constant rate into a select number of boreholes. An inflatable-packer system was used to isolate $0.3 \mathrm{~m}$ long test intervals in the boreholes, allowing water to be introduced at a prescribed depth. An overflow line, connecting the test interval through the packer to a container located at the surface (which was kept at an elevation lower than the test interval), prevented water from ponding more than $0.05 \mathrm{~m}$ deep within the horizontal $0.076 \mathrm{~m}$ diameter boreholes. It also prevented water from being forced under pressure into the formation by the pump if the pumping rate exceeded the infiltration capacity of the rock (i.e., saturated conditions). Water was pumped to the test interval 
at the desired liquid-release rate from a reservoir resting on an electronic balance. The balance and corresponding data acquisition system were used to measure and record the mass and rate of water dispensed during the test. Various dyes were used during the study to stain the flow path traveled by the water and to identify individual liquid-release events.

\subsection{Niche Excavation Activities}

The niche consists of an $8.2 \mathrm{~m}$ long by $4 \mathrm{~m}$ wide by $3.3 \mathrm{~m}$ high drift shown in Figure 1 and 2 constructed along the west side of the ESF Main Drift. The niche was mined dry to map and photograph the distribution of fractures and dye within the rock resulting from the preexcavation liquid-release tests. A mechanical device called a roadheader was used to advance the excavation by making small cuts of rock ranging from 0.15 to $0.2 \mathrm{~m}$ in depth. Dye was observed along individual fractures (as well as along networks of fractures) to depths ranging from 0 to $2.6 \mathrm{~m}$ below the release points.

\subsection{Postexcavation Seepage Tests}

Air-injection tests were repeated in boreholes UL, UM, and UR after the niche was excavated to determine the postexcavation distribution of air permeabilities. A dramatic increase in formation air permeability was observed at other sites within the Tptpmn when similar drifts were excavated adjacent to test boreholes (as reported by Cook [2000]). The geometric mean air permeability increased by nearly two orders of magnitude after construction at these locations, probably resulting from mining-induced damage to the surrounding rock [Wang and Elsworth, 1999]. Although postexcavation air-permeability data have yet to be published for our site, a similar increase in air permeability was observed.

An extensive series of liquid-release tests was performed after the niche was constructed to evaluate the capillary barrier concept and to quantify the amount of water seeping into the niche 
from a localized source of water. In addition, the tests were used to establish the threshold rate at or below which water would no longer seep into the mined opening.

A seepage test was typically conducted by pumping water at a constant rate into a select test interval in borehole UL, UM, or UR. Water migrating from the release point to the ceiling that dripped into the niche was collected in a capture system. The capture system consisted of 44 $0.30 \mathrm{~m}$ wide by $1.20 \mathrm{~m}$ long trays constructed of transparent lexan plastic hung from an aluminum frame. In turn, the aluminum frame was suspended on poles so that the top of the capture system was approximately 0.4 to $1.0 \mathrm{~m}$ below the ceiling at the walls and centerline of the niche, respectively. The plastic trays were about $0.2 \mathrm{~m}$ deep and divided into four separate compartments, each 0.30 by $0.30 \mathrm{~m}$. Figure 2 shows a plan view of the capture system and its position relative to the overlying boreholes, test intervals, and the boundary of the niche. Electronic balances were used to monitor the mass and rate that water was pumped into the borehole as well as return flow to the surface through the overflow line (if it occurred). A third balance was used to continuously monitor and record the seepage mass and rate throughout the test.

Eleven liquid-release tests were performed on three test intervals positioned above the niche (shown in Figure 2). The tests ranged from 1.2 to 24 days in length with the average duration of all the seepage tests equal to 10.3 days. The liquid-release rates for all the tests ranged from 7.8E-06 to $9.2 \mathrm{E}-05 \mathrm{~kg} / \mathrm{s}$. The seepage tests were stopped when the seepage rate into the niche stabilized (as illustrated in Figure 3 for test zone UR), or when the zone did not seep after two weeks of continuous injection. The volume of water released ranged from 8.9 to 40.2 liters per test.

The seepage tests were conducted with the bulkhead doors at the entrance to the niche closed and sealed. Also, the air space within the niche was artificially humidified to increase the 
relative humidity as high as practical to minimize the effects of evaporation resulting from ESF ventilation. The test conditions (e.g., high humidity and low evaporation rates) are representative of steady seepage into a drift that could potentially occur after the repository is closed, the heat load and temperature rise from the decaying waste have dissipated, and air in the sealed repository equilibrates with the surrounding rock at or near $100 \%$ relative humidity. The relative humidity and temperature of the air within the niche were monitored from October 1999 through June 2000 spanning all but the last test when the instrument was removed for recalibration.

Figure 4 shows the trends in the relative humidity and temperature data for the monitoring period. Examination of this plot shows that the temperature of the air is quite stable decreasing slightly throughout the cooler winter months then increasing as the warmer summer months are approached. In contrast, the relatively humidity exhibits much larger fluctuations and a long-term increasing trend. The large fluctuations in relative humidity can be attributed to movement of air into and out of the niche through the fractures and porous floor around and beneath the bulkhead, respectively. The dry air in the ESF (typically $<40 \%$ relative humidity) moves around the bulkhead through the adjacent rock and dilutes the moist air within the niche during periods of high barometric pressure. In contrast, the moist air in the rock enters the niche through the walls of the excavation and increases the relative humidity during periods of low barometric pressure in the ESF. The long-term increase in relative humidity probably resulted from the following:1) the atmosphere within the niche is slowly coming in equilibrium with the surrounding rock matrix, which has a high matric potential corresponding to a relative humidity of 99 percent or greater in the vapor-filled pore spaces; and 2) continuous humidification of the niche starting in early March 2000 (prior to March the niche was only humidified during a test). 
A container of water was placed on a balance inside the niche and at other locations in the ESF to measure the water lost to evaporation because of changing relative humidity conditions. The pan was also used continuously throughout the final test to directly measure the evaporation rate when the humidity probe was being recalibrated. As expected, the evaporation mass flux plotted in Figure 5 increases as the relative humidity inside the niche decreases. A linear regression was performed on the data set to define the empirical relation between relative humidity $(\mathrm{RH}, \%)$ and evaporation mass flux $\left(\mathrm{q}_{\mathrm{e}}, \mathrm{kg} / \mathrm{s} / \mathrm{m}^{2}\right)$ shown graphically by the line in Figure 5 and expressed mathematically by the regression equation:

$$
\mathrm{q}_{\mathrm{e}}=(-4.26 \mathrm{E}-07) \mathrm{RH}+4.28 \mathrm{E}-05
$$

(correlation coefficient, $\mathrm{R}^{2}$, equal to 0.997 ). A linear relation between $\mathrm{RH}$ and $\mathrm{q}_{\mathrm{e}}$ is expected assuming evaporation from the free-water surface in the pan is diffusion dominated (i.e., a boundary layer exists of approximately constant thickness). This assumption is based on the condition that the drift was not ventilated during the tests. The evaporation fluxes (expressed in $\mathrm{mm} /$ day) obtained using Equation (1) are within 25 percent of the values obtained using the modified Penman equation [Penman, 1956] for relative humidities greater than 80 percent, typical of test conditions. The modified Penman equation is an empirical relation between evaporation flux and the vapor pressure gradient above a free water surface commonly used to predict evaporation from surface water reservoirs.

\section{Determination of Seepage Threshold Flux $\left(\mathbf{K}_{\infty *}\right)$}

$\mathrm{K}_{\infty}$ was determined by performing multiple seepage tests at different liquid-release fluxes on a given test interval. The liquid-release flux $\left(\mathrm{q}_{\mathrm{r}}, \mathrm{m} / \mathrm{s}\right)$ is defined as the mass rate that water was released into the borehole $\left(\mathrm{Q}_{\mathrm{r}}, \mathrm{kg} / \mathrm{s}\right)$ divided by the wetted cross-sectional area of the test interval (5.3E-02 $\left.\mathrm{m}^{2}\right)$ and the density of water $\left(\rho, 998 \mathrm{~kg} / \mathrm{m}^{3}\right)$. We assume in our analysis that $\mathrm{q}_{\mathrm{r}}$ 
represents the percolation flux (i.e., $\mathrm{q}_{\mathrm{r}} \approx \mathrm{K}_{\infty}$, see Section 5.1 and 6.1 for limitations associated with this assumption). Initial tests were conducted at high liquid-release fluxes, with subsequent tests performed at lower fluxes until water no longer seeped into the opening (i.e., zero seepage) or seepage was minimal. A four-week inactive period separated individual tests conducted on the same test interval, allowing the water within the rock to partially re-equilibrate with the surrounding rock matrix and atmosphere within the niche, thus reducing the affects of wetting history.

The seepage percentage, $v_{i}$, defined as the mass rate that water dripped into the opening $\left(Q_{d}\right.$, $\mathrm{kg} / \mathrm{s}$ ) times 100 divided by $\mathrm{Q}_{\mathrm{r}}$, was computed for each test and ranged from 0 to $71.6 \%$. Figure 6a shows $v_{i}$ along with its corresponding value of $q_{r}$ for each seepage test and test interval (designated UL, UM or UR). Figure 6a indicates that $v_{i}$ decreases with decreasing $q_{r}$, as expected when the seepage threshold is approached and the capillary barrier becomes more effective in reducing seepage. A regression analysis was performed on the data for each test interval to define $\mathrm{K}_{\infty} *$. The resulting regression equation of the form

$$
\mathrm{v}_{\mathrm{i}}=\mathrm{A} \ln \left(\mathrm{q}_{\mathrm{r}}\right)+\mathrm{B}
$$

was solved for $\mathrm{q}_{\mathrm{r}}=\mathrm{K}_{\infty^{*}}$ by setting $\mathrm{v}_{\mathrm{i}}=0$. Here, $\mathrm{A}$ and $\mathrm{B}$ are the slope and $\mathrm{y}$-intercept, respectively, from the regression. Table 1 summarizes the results of the regression and the magnitude of the seepage threshold for the three test intervals, which range from 1.2E-07 to $1.6 \mathrm{E}-07 \mathrm{~m} / \mathrm{s}(3,870$ to $5,100 \mathrm{~mm} /$ year $)$.

\subsection{Note on Area Used to Define $q_{r}$ and $K_{\infty *}$}

The true cross-sectional area of the flow path between the borehole and ceiling of the niche is not known. Therefore, it is important to realize that substitution of the wetted cross-sectional of the borehole for the true area produces an estimate of $\mathrm{q}_{\mathrm{r}}$ and the desired seepage threshold 
value, $\mathrm{K}_{\infty}$. By defining or normalizing $\mathrm{q}_{\mathrm{r}}$ by the wetted area of the borehole, we have assumed that the formation adjacent to the borehole is homogeneous and isotropic and that the borehole's wetted side-wall area is available to conduct fluid.

Field observations lead us to believe that the former assumption relating to the uniformity of the fracture system may be justified within limits. Figure 7 shows a plan view of the niche ceiling as viewed from below within the excavation. The contour lines represent the leading edge of the advancing wetting front at different times during a seepage test as the plume spreads across the niche ceiling. Visible fractures mapped prior to testing are also shown in Figure 7 . The symmetry of the wetted area (which is not limited to this test) lends support to the assumption that the fracture system in close proximity to the opening appears to be well developed resulting in a homogeneous, isotropic pattern of fluid flow. The average speed at which the leading edge of the plume moves across the ceiling (i.e., $153,000 \mathrm{~mm} / \mathrm{yr}$ ) is much faster than what could be transmitted through the rock matrix alone given its very low saturated hydraulic conductivity $(1.2 \mathrm{~mm} / \mathrm{yr})$. This suggests that the symmetry of the wetted area is not simply caused by imbibition of water across the ceiling through the relatively homogenous rock matrix. Rather, fine fractures or surface films must be present for the water to be transmitted quickly along the ceiling in the observed uniform pattern. Laboratory experiments conducted by Tokunaga and Wan [1997] and Tokunaga et al. [2000] show that high film velocities can occur across natural and artificial fracture surfaces at high saturations, suggesting that film flow can be an important contributor to fast and preferential flow through the unsaturated zone.

The second assumption employed in the definition of $\mathrm{q}_{\mathrm{r}}$ and the derivation of $\mathrm{K}_{\infty}$ is that the entire cross-sectional area of the wetted borehole is available to transmit fluid. In reality, the fractures transmit fluid through a much smaller area compared to the surface area of the borehole 
(which consists primarily of very low permeability matrix), resulting in higher fluxes than those reported in Table 1. In addition, preferential flow paths may develop within unsaturated fractures decreasing the flow path area and increasing the flux even further ( $\mathrm{Su}$ et al., 1999). Therefore, the liquid-release fluxes and seepage threshold values reported in Table 1 underestimate the true values as a result of overestimating the flow-path area. Underestimating the seepage threshold flux is conservative (and thus desirable) because it increases the range of fluxes that can potentially produce seepage into the drift.

\subsection{Correction for Evaporation}

Evaporation of water from the surface of the ceiling during a seepage test can have the opposite effect that overestimation of the release area has on $\mathrm{K}_{\infty^{*}}$. Evaporation decreases the seepage rate into the drift $\left(\mathrm{Q}_{\mathrm{d}}\right)$ causing the lines shown in Figure $6 \mathrm{a}$ to be shifted to the right potentially resulting in an over estimation of $\mathrm{K}_{\infty^{*}}$. Over estimating $\mathrm{K}_{\infty^{*}}$ is not desirable because it decreases the range of $\mathrm{K}_{\infty}$ values that potentially produce seeps.

The $\mathrm{Q}_{\mathrm{d}}$ data measured during the tests were adjusted for evaporation by substituting the average relative humidity measured during each experiment into Equation (1) to calculate an average evaporation flux for each test. These values were multiplied by the maximum drip area observed on the niche ceiling during each test to calculate the evaporation rate $\left(\mathrm{Q}_{\mathrm{e}}\right)$. Adding $\mathrm{Q}_{\mathrm{e}}$ to $\mathrm{Q}_{\mathrm{d}}$, then multiplying the result by 100 and dividing by $\mathrm{Q}_{\mathrm{r}}$ yields the seepage percentage plots corrected for evaporation shown in Figure $6 \mathrm{~b}$. Using the same process outlined in Section 5., a linear regression was conducted on the seepage data to produce estimates of $\mathrm{K}_{\infty}$ corrected for evaporation reported in Table 1 and shown graphically by the $\mathrm{x}$-intercepts of the regression lines on Figure $6 \mathrm{~b}$. Comparison of the $\mathrm{K}_{\infty} *$ values derived from the evaporation adjusted seepage data (Figure 6b) to those that were not (Figure 6a) indicates the correction resulted in a relatively 
minor change in the seepage thresholds. $\mathrm{K}_{\infty} *$ values from tests conducted on borehole UR exhibited the maximum change decreasing by a factor of 2.4 from $1.23 \mathrm{E}-07$ to $5.07 \mathrm{E}-08 \mathrm{~m} / \mathrm{s}$ $(3,870$ to $1,600 \mathrm{~mm} / \mathrm{yr})$.

It is important to note that the evaporation analysis does not include the results from two tests that did not seep (shown as an open diamond and square on Figure 6b). This was to prevent these data points from influencing the $\mathrm{x}$-intercept and thus the value of $\mathrm{K}_{\infty}$ - derived from the second regression. These data could not be adjusted for evaporation because dripping did not occur during these tests so the drip area could not be defined and an evaporation rate could not be calculated. It was also assumed that evaporation did not affect $\mathrm{Q}_{\mathrm{r}}$, the rate that water was released into the borehole.

\section{Interpretation of Seepage Test Data}

\subsection{Capillary Strength of the Fractures $\left(\alpha^{-1}\right)$}

The seepage threshold fluxes were interpreted using the solution formulated by Philip et al. [1989a]. This solution describes the exclusion of water from a cylindrical cavity buried in a homogeneous porous medium as a result of a capillary barrier. Their solution is based on several important assumptions including the medium surrounding the underground opening is homogeneous and isotropic, the medium is infinite in extent, and a spatially uniform flux $\left(\mathrm{K}_{\infty}\right)$ exists far removed from the cavity.

Philip et al. [1989a] note that their solution is valid for a heterogeneous medium as long as the medium is homogeneous within a few characteristic lengths of the cavity wall. The symmetry of the wetted area shown in Figure 7 supports the assumption that fracture or film flow in close proximity to the opening appears to be well developed resulting in a homogeneous, isotropic pattern of fluid migration. Although not infinite in extent, according to Beusch and Spengler 
[1998] the Tptmn is approximately $40 \mathrm{~m}$ thick. The niche is located near the center of this unit creating a minimum distance of $15 \mathrm{~m}$ between the niche ceiling and the overlying gradational contact with the upper lithophysal zone of the Tpt. In addition, the Tpt is over $300 \mathrm{~m}$ thick at this location supporting the second assumption. The third condition assumes that a spatially uniform flux exists far removed from the cavity. This condition is not satisfied by the small-scale, localized liquid-release fluxes imposed during our experiments (i.e., $\mathrm{q}_{\mathrm{r}}$ is assumed to equal $\mathrm{K}_{\infty}$ ). However, in light of the ultimate goal of estimating the unsaturated capillary strength $\alpha^{-1}$ of the formation, we chose to accept this assumption, and instead provide the caveat that the results that follow are specific to our test conditions.

Philip et al.'s [1989a] steady-state solution relates $\mathrm{K}_{\infty} *$ to the saturated hydraulic conductivity, $\mathrm{K}_{\mathrm{o}}$, and a scaling parameter, $\mathrm{s}$, that accounts for both the size of the opening and capillary properties of the porous medium:

$$
\mathrm{K}_{\infty^{*}}=\mathrm{K}_{\mathrm{o}}\left[\vartheta_{\max }(\mathrm{s})\right]^{-1}
$$

Here, $\mathrm{s}$ is the value of the dimensionless cavity length and $\vartheta_{\max }$ is the maximum value of the dimensionless potential $(\vartheta)$ at the boundary of the cavity. The dimensionless cavity length, s, is a measure of the relative importance of gravity and capillarity in governing flow through the unsaturated medium. As $s \rightarrow 0$, which may occur either because the capillary strength of the medium is very large $\left(\alpha^{-1} \rightarrow \infty\right.$, e.g., fine textured soil) or because the cavity dimensions are very small, capillarity dominates the flow process. In contrast, when $s \rightarrow \infty$, gravity dominates the flow process either because of small-formation capillary strength $\left(\alpha^{-1} \rightarrow 0\right.$, e.g., coarse-textured soil) or large-diameter cavity. The dimensionless cavity length, $\mathrm{s}$, is related to sorptive number $\alpha$, the reciprocal of the capillary strength $\left(\alpha^{-1}\right)$ and a characteristic length of the cavity $\ell$, by 


$$
\mathrm{s}=0.5 \alpha \ell
$$

In turn, the sorptive number $\alpha$ enters into the exponential representation of the unsaturated hydraulic conductivity as a function of water potential [Gardner, 1958]:

$$
\mathrm{K}(\psi)=\mathrm{K}_{\mathrm{o}} \exp \left(\alpha\left(\psi-\psi_{\mathrm{e}}\right)\right)
$$

where $\mathrm{K}_{\mathrm{o}}$ should be set equal to the saturated hydraulic conductivity of the soil and $\psi_{\mathrm{e}}=0$, if the medium does not exhibit a significant air entry potential $\left(\psi_{\mathrm{e}}\right)$. In contrast, $\mathrm{K}_{\mathrm{o}}$ is set equal to the unsaturated hydraulic conductivity corresponding to the air entry value when the air entry potential is significant [Pullan, 1990].

When $\mathrm{s}$ is large in Equation (3), a boundary layer adjoining the ceiling of the cavity surface will develop. This allows the steady-flow equation to be replaced by a readily solved boundarylayer equation. The asymptotic expansion of $\vartheta_{\max }$ for large values of $s$ is

$$
\vartheta_{\max }(\mathrm{s})=2 \mathrm{~s}+2-(1 / \mathrm{s})+\left(2 / \mathrm{s}^{2}\right)-\ldots
$$

Philip et al. [1989a] show that the first three terms on the right hand side of Equation (6) produce an adequate engineering estimate that is within $10 \%$ or better of the exact value of $\vartheta_{\max }$, when $s \geq 1$. Therefore, using Equation (4) and appropriate values for $\mathrm{K}_{\infty^{*}}, \ell$, and $\mathrm{K}_{0}$, we can compute the capillary strength for the porous medium from Equations (3), (4) and the first three terms in (6). This technique was utilized to compute the $\alpha^{-1}$ values reported in Table 1 using the values for $\mathrm{K}_{\infty^{*}}$ derived in Section 5 . The $\mathrm{K}_{\mathrm{o}}$ values were derived from postexcavation airinjection tests summarized in Table 1 and a value of 2 meters was used for $\ell$, which is approximately equal to the radial curvature of the niche ceiling. By taking the reciprocal of the 
$\alpha^{-1}$ reported in Table 1 , which in our case also equals s, all the s-values are greater than one, justifying the use of Equation (6).

Philip [1989c] reports that $\alpha^{-1}$ ranges from $0.05 \mathrm{~m}$ or less for coarse-grained soils to $5 \mathrm{~m}$ or more for fine-textured soils. In comparison, the values reported in Table 1 range from 0.001 to $0.06 \mathrm{~m} \mathrm{(13} \mathrm{to} 653 \mathrm{~Pa}$ ) for the fractures tested, with the lower bound below that normally reported in the literature for soils. Philip [1989c] and White and Sully [1987] recognized that $\alpha^{-1}$ is a K-weighted mean soil-water potential directly related to the macroscopic capillary length, or pore radius $\mathrm{r}$ of the medium, as follows:

$$
2 \alpha^{-1}=\frac{2 \gamma \cos (\theta)}{\rho g r}
$$

where $\gamma, \rho$ and $\theta$ are the surface tension, density, and contact angle of the fluid, respectively, and $\mathrm{g}$ is gravitational acceleration. The right-hand-side of Equation (7) is known as Laplace's capillary formula, which is equal to the height of fluid rise in a small diameter cylindrical tube. Equation (7) can also be used to estimate the height of fluid rise between two smooth parallel plates analogous to a fracture by substituting the aperture $b$, or separation distance between plates for $r$ in Equation (7).

Bouwer [1966] and Raats and Gardner [1971] described the macroscopic capillary length, and hence $2 \alpha^{-1}$, as a "mean" height of capillary rise above a water table, or the "mean" air entry head. In our case, the significance of $2 \alpha^{-1}$ is that it represents the mean height that water will rise in the fractures above the drift because of the capillary barrier. This implies that even though the capillary strength of the fracture system is very weak compared to other porous media (as evidenced by the range of $\alpha^{-1}$ values reported in Table 1), the capillarity of the fractures is strong 
enough that the capillary barrier is somewhat effective (as evidenced by the existence of the seepage threshold).

\subsection{Limits of Capillary Theory}

Figure 8 was generated by plotting the $K_{\infty} *$ values derived in Section 5 along with their corresponding $\mathrm{K}_{\mathrm{o}}$ values reported in Table 1 . The significance of the line in Figure 8 is that it corresponds to the smallest value of $\alpha^{-1}$ that can be obtained given the limited range of validity for the capillary mechanism using Laplace's formula. Wang and Narasimhan [1993] show that when the fracture aperture is very large, the radial curvature of the fluid meniscus between two parallel plates will be very large and the capillary effect will be negligible. Using Laplace's formula, they determined for a wetting fluid of contact angle zero (i.e., $\theta=0$ in (7)) that the capillary mechanism is no longer valid when the maximum aperture $b_{\max }$ between two smoothwalled parallel plates exceeds

$$
\mathrm{b}_{\max }=\left(\frac{2 \gamma}{\rho g}\right)^{1 / 2}
$$

For $\gamma=0.072 \mathrm{~kg} / \mathrm{s}^{2}, \rho=998 \mathrm{~kg} / \mathrm{m}^{3}$, and $\mathrm{g}=9.8 \mathrm{~m} / \mathrm{s}^{2}$ the nominal aperture size is $3.84 \mathrm{~mm}$, which, using Equation (7), corresponds to a limiting value for $\alpha^{-1}$ equal to $0.0019 \mathrm{~m}$. The line on Figure 8 represents the practical limit of Equation (3) calculated using the limiting value of $\alpha^{-1}$ derived from Equations (7) and (8). Therefore, values of $\alpha^{-1}$ less than $0.0019 \mathrm{~m}$ correspond to nominal apertures that are greater than $3.84 \mathrm{~mm}$, the point at which capillary forces vanish and gravity forces dominate flow. The UM test data are slightly above the line in Figure 8 . This implies that gravity forces, possibly resulting in film flow along the fracture surface under high saturation conditions dominate fluid flow through this high permeability feature. 


\section{Field Observations-Physical Evidence of a Capillary Barrier}

Thus far, we have shown that the seepage threshold flux can be measured experimentally in the field, then analyzed and interpreted using a model incorporating the capillary-barrier concept. Two types of field evidence are presented below, lending support to the conclusion that a barrier is present.

\subsection{Lateral Spreading of Wetted Area}

Figure 9 shows a plan view of the niche ceiling viewed from below within the niche. It was created from a time-lapse video recording of the niche ceiling taken during the final liquidrelease test conducted on interval UL. The contour lines represent the leading edge of the advancing wetting front at different times during the test as the plume spreads across the niche ceiling (defined by points $(0,8) ;(6,8) ;(6,14) ;$ and $(0,14)$ in the figure). Visible fractures are also shown in Figure 9.

The wetting front arrived at the niche ceiling in 4.5 hours (Figure 9, point A) and began dripping into the opening within 26.5 hours of starting the release. The water was released at a constant rate $(1.92 \mathrm{E}-05 \mathrm{~kg} / \mathrm{s})$ into borehole UL located about $0.7 \mathrm{~m}$ above the niche ceiling. Over the next 12.2 days, the plume spread laterally across the ceiling reaching the left wall (defined by line $(0,8) ;(0,14))$ at point $B$ and the terminal face of the niche (defined by line $(0,14) ;(6,14))$ at point $\mathrm{C}$ in Figure 9. The plume continued to grow moving another 0.3 to $0.8 \mathrm{~m}$ down the sidewall and terminal face of the niche to Points D and E, respectively in another 10 days before the test was terminated. The test ran for 23.9 days and the plume covered an area of $3.3 \mathrm{~m}^{2}$.

We would expect lateral spreading of the plume across the ceiling of the niche (as shown in Figure 9) if a capillary barrier were present. Lateral spreading of the wetted area was observed during all of the tests including those that did not seep. It is important not to over interpret the 
data, since an alternative explanation for spreading is that the water moved laterally away from the point of release because of water imbibition by the relatively dry matrix and fractures in the skin adjacent to the opening. Therefore, lateral spreading of the wetted area should be considered "weak" evidence that a capillary barrier was present.

\subsection{Wetting-Front Movement Up Fractures}

The most compelling evidence of capillary barrier formation was observed when a small breakout in the ceiling was present. A breakout is a location where a block of rock falls out of the ceiling during the mining process, producing a void that extends upward beyond the relatively flat section of the ceiling. Typically, the rock block drops from the ceiling, exposing high- and low- angle fractures extending upward into the rock mass above the niche. When the fracture surfaces are exposed directly beneath a test interval, they provide an opportunity to observe the arrival of the wetting front in three-dimensions (3-D). In general when a breakout is not present, only a two-dimensional (2-D) plan view of the wetted area is exposed on the niche ceiling.

Figure 10 provides an example of a 3-D vantage point and the wetted area that resulted from a liquid-release test. Although it is difficult to conceptualize using a flat 2-D drawing, a breakout zone is present in Figure 10. The illustration was created from digital photographs that were taken looking up at the ceiling, with the breakout zone extending into the plane of the page. The axis of the borehole was painted on the niche ceiling and appears on the drawing. Within the breakout zone are several high and low-angle fractures, including a low-angle fracture whose face is part of the niche ceiling within the breakout (shaded area with small arrow labelled " $\left.\mathrm{v}_{33} \mathrm{o}^{\circ}\right)$. The solid arrows designated with the letter " $\mathrm{v}$ " on Figure 10 are drawn parallel to the dip direction of both high- and low-angle fractures, but point up into the breakout zone rather than down dip (the standard convention). The dip angle (in degrees) is also provided as a subscript. 
Arrows labeled with the letter " $\mathrm{h}$ " are drawn parallel to the near-horizontal plane forming the niche ceiling.

Referring to Figure 10, the wetting front arrived at the niche ceiling beneath the test interval in approximately 3.5 minutes. The wetting front arrived at the location noted on the figure near the intersection of the low-angle fracture (shaded area) with the niche ceiling. Surprisingly, within a few seconds, the wetting front was observed moving up several small fractures that terminated at the face of the breakout. Approximately 20 seconds after the wetting front arrived, the wetting front reached the position shown by the solid black line on Figure 10. The dashed arrows show the direction that the wetting front traveled. Figure 10 also shows the position of the wetting front about 2 minutes after the wetting front arrived (dotted lines), when water began dripping into the drift. The wetting front moved an additional $0.08 \mathrm{~m}$ up the fine fracture from Location 1 to Location 2 (shown next to the arrow in Figure 10) in 1.33 minutes.

It is important to emphasize that the wetting front arrived first at the ceiling of the niche and then was observed migrating up several fine fractures exposed in the sidewall of the breakout. This demonstrates that the water saturation was building up within the fracture network for approximately 2 minutes before water began dripping into the capture system. These observations provide stronger evidence that a capillary barrier formed for a brief time and then collapsed once saturated conditions were reached locally within the fracture system.

\section{Conclusions}

Drift-scale seepage tests performed at Yucca Mountain were used to determine that a seepage threshold flux $\left(\mathrm{K}_{\infty}\right)$ exists, defined in this paper as the percolation flux below which water does not drip into an underground waste emplacement drift. The seepage threshold is a result of a capillary barrier at the drift ceiling that causes water to be held under tension in the 
formation instead of dripping into the opening. The movement of water up fine fractures exposed in the ceiling and lateral spreading of the wetted area across the ceiling provides evidence that a capillary barrier exists.

Seepage data measured during this study were adjusted for evaporation using a simple empirical approach. Evaporation decreases the amount of water that drips into the opening producing inflated seepage threshold fluxes (as noted by comparing the average thresholds reported in Table 1). An inflated $K_{\infty^{*}}$ is neither desirable nor conservative because it results in a smaller range of fluxes that lead to seepage into a potential waste emplacement drift.

The effectiveness of the capillary barrier depends on whether there is sufficient lateral permeability or connectivity of the fracture system in the immediate vicinity of the drift to move water laterally around the opening. Field observations indicate that there is sufficient permeability for the wetting front to spread laterally from beneath the test interval where water was introduced above the drift to the sidewalls 1 to 2 meters away. Under high saturation conditions, water movement around the drift can also be enhanced and seepage can be reduced further by fast and preferential surface film flow (Tokunaga and Wan [1997], Tokunaga et al. [2000]) along the drift ceiling and through highly transmissive surface coatings on natural fractures (Tokunaga and Wan, 2001) intersecting this surface.

The effectiveness of the capillary barrier also depends upon the capillary strength $\left(\alpha^{-1}\right)$ of the fractures, a measure of the water retention properties of the rock. Test data were interpreted using an analytical model of a cylindrical drift buried in a homogeneous unsaturated porous medium to derive test-specific estimates of $\alpha^{-1}$. Although (strictly speaking) a fractured rock system is not typically homogeneous, field observations indicate that the wetted area spread in a surprisingly symmetric pattern away from the point of release along the drift ceiling. This 
indicates that in close proximity to the excavation, an interconnected network of fractures potentially exist or surface film flow dominates such that a homogeneous and isotropic pattern of fluid migration develops.

The analysis produced test-specific estimates of the quantity $\alpha^{-1}$ ranging from 0.001 to $0.06 \mathrm{~m}$, the lower limit of the range represents a flow system driven solely by gravity forces. It is important to recognize that under steady-state conditions a seepage threshold theoretically should not exist for a solely gravity-driven flow system (100 percent of the water should seep in this case). Surprisingly, seepage tests conducted on interval UM believed to be representative of just such a gravity-driven flow system (based on its very weak water retention properties, i.e., small $\alpha^{-1}$ value), exhibited a measurable seepage threshold. A maximum of 35 percent seepage was observed for this zone and a seepage threshold was obtained (no seepage was observed) after nearly 20 days of continuous injection at the lowest applied rate.

This implies that the matrix, fine fractures or surface films that are present or develop at the outlet to the dripping fracture must be capable of transmitting sufficient quantities of water by capillary and/or gravity forces along the drift ceiling thus reducing seepage levels below 100 percent. Given the fact that the saturated hydraulic conductivity of the matrix is five to six orders of magnitude less than the fractures, it is difficult to accept that lateral diversion of the relatively high liquid fluxes applied during the tests is strictly governed by matrix imbibition. The role of higher permeability features (such as mining-induced fine fractures or surface-zones along natural fractures at the drift ceiling) in diverting water seems more plausible as does fast lateral movement of water along the ceiling as thin surface films. In reality, all four mechanisms probably play an important role (depending upon the magnitude of the percolation flux) in reducing seepage and promoting lateral flow around an underground opening in the unsaturated zone at Yucca Mountain. Future work includes the evaluation of the wetting front position and 
its rate of movement across the ceiling in an attempt to determine the dominant flow mechanism(s).

It is important to recognize that the magnitude of the $\mathrm{K}_{\infty^{*}}$ values reported in this paper are dependent upon the scale of the tests, the test conditions and the manner in which we define the liquid-release flux and linear model used to estimate $\mathrm{K}_{\infty}$ (Section 5.1). Every attempt was made to underestimate the true magnitude of $\mathrm{K}_{\infty *}$ producing a larger range of fluxes than would normally result in seepage into the drift. We have intentionally avoided comparing our testspecific $\mathrm{K}_{\infty}$ values to estimates of the percolation flux from Yucca Mountain because of these limitations.

\section{Acknowledgments}

Many thanks to LBNL team members John Clyde, Paul Cook, Steve Flexser, Randy Hedegaard, Lee Jacobs, Don Lippert, Phil Rizzo, and Ray Solbau for fabricating the test equipment, assisting with the field work, and preparing figures used in this report. We also thank Tetsu Tokunaga for his thorough and constructive review of this paper. This work was supported by the Director, Office of Civilian Radioactive Waste Management, U.S. Department of Energy, through Memorandum Purchase Order EA9013MC5X between Bechtel SAIC Company, LLC and the Ernest Orlando Lawrence Berkeley National Laboratory (Berkeley Lab). The support is provided to Berkeley Lab through the U.S. Department of Energy Contract No. DE-AC0376SF00098. 


\section{References}

Birkholzer, J., G. Li, C. -F. Tsang and Y. Tsang, Modeling studies and analysis of seepage into drifts at Yucca Mountain, J. Contam. Hydrol., 38(1999), 349-384, 1999.

Bouwer, H., Rapid field measurement of air entry value and hydraulic conductivity of soil as significant parameters in flow system analysis, Water Resour. Res., 2(4), 729-738, 1966.

Buesch, D. C., R. W. Spengler, T. C. Moyer, J. K. Geslin, Proposed stratigraphic nomenclature and macroscopic identification of lithostratigraphic units of the Paintbrush Group exposed at Yucca Mountain, Nevada, U.S. Geol. Surv. Open File Rep. 94-469, 1996.

Buesch, D. C., and R. W. Spengler, Character of the middle nonlithophysal zone of the Topopah Spring Tuff at Yucca Mountain, in Proceedings of the Eighth International Conference on High-Level Radioactive Waste Management, Amer. Nuc. Soc., Las Vegas, Nevada, May 1114, 592-593, 1998.

Cook, P., In situ pneumatic testing at Yucca Mountain, Int. J. Rock Mech. Mining Sci., 37(2000), $357-367,2000$.

DOE, Viability assessment of a repository at Yucca Mountain, Volume 1, introduction and site characteristics, U.S. Dept. Energy Office Civilian Radioactive Waste Management, DOE/RW0508/V1, 171 pp., 1998.

Finsterle, S., Using the continuum approach to model unsaturated flow in fractured rock, Water Resour. Res., 36(8), 2055-2066, 2000

Flint, L. E., Characterization of hydrogeologic units using matrix properties, Yucca Mountain, Nevada, U.S. Geol. Surv. Water-Resour. Invest. Rep. 97-4243, 64 pp., 1998.

Gardner, W. H. and J. C. Hsieh, Water movement in soil, film, Washington State Univ., Pullman, 1959. 
Gardner, W. R., Some steady-state solutions of the unsaturated moisture flow equation with application to evaporation from a water table, Soil Sci., 85, 228-232, 1958.

Ho, C. K., Evaporation of pendant water droplets in fractures, Water Resour. Res., 33(12), 2665$2671,1997$.

Ho, C. K., and S. W. Webb, Capillary barrier performance in heterogeneous porous media, Water Resour. Res., 34(4), 603-609, 1998.

Hughson, D. L., and F. T. Dodge, The effect of cavity wall irregularities on seepage exclusion from horizontal cylindrical underground openings, J. Hydrol., 228(2000), 206-214, 2000.

Knight, J. H., J. R. Philip and R. T. Waechter, The seepage exclusion problem for spherical cavities, Water Resour. Res., 25(1), 28-37, 1989.

Miyazaki, T., Water flow in unsaturated soil in layered slopes, J. Hydrol., 102(1988), 201-214, 1988.

Montazer, P., and W. E. Wilson, Conceptual hydrologic model of flow in the unsaturated zone, Yucca Mountain, Nevada, U.S. Geol. Surv. Water Resour. Invest. Rep. 84-4345, 55 pp., 1984.

Oldenburg, C. M., and K. Pruess, On numerical modeling of capillary barriers, Water Resour. Res., 29(4), 1045-1056, 1993.

Or, D., and T. A. Ghezzehei, Dripping into subterranean cavities from unsaturated fractures under evaporative conditions, Water Resour. Res., 36(2), 381-393, 2000.

Philip, J. R., Linearized unsteady multidimensional infiltration, Water Resour. Res., 22(12), $1717-1727,1986$.

Philip, J. R., The seepage exclusion problem for sloping cylindrical cavities, Water Resour. Res., 25(6), 1447-1448, 1989a. 
Philip, J. R., Asynptotic solutions of the seepage exclusion problem for elliptic-cylindrical, spheroidal, and strip- and disc-shaped cavities, Water Resour. Res., 25(7), 1531-1540, $1989 \mathrm{~b}$.

Philip, J. R., The scattering analog for infiltration in porous media, Rev. Geophys., 27(4), 431$447,1989 \mathrm{c}$.

Philip, J. R., Some general results on the seepage exclusion problem, Water Resour. Res., 26(3), $369-377,1990$.

Philip, J. R., Seepage shedding by parabolic capillary barriers and cavities, Water Resour. Res., 34(11), 2827-2835, 1998.

Philip, J. R., J. H. Knight, and R. T. Waechter, Unsaturated seepage and subterranean holes: conspectus, and exclusion problem for cylindrical cavities, Water Resour. Res., 25(1), 16-28, 1989a.

Philip, J. R., J. H. Knight, and R. T. Waechter, The seepage exclusion problem for parabolic and paraboloidal Cavities, Water Resour. Res., 25(4), 605-618, $1989 \mathrm{~b}$.

Pullan, A. J., The quasilinear approximation for unsaturated porous media flow, Water Resour. Res., 26(6), 1219-1234, 1990.

Raats, P. A. C., and W. R. Gardner, Comparison of emperical relationships between pressure head and hydraulic conductivity and some observation on radially symmetric flow, Water Resour. Res., 7(4), 921-928, 1971.

Ross, B., The diversion capacity of capillary barriers, Water Resour. Res., 26(10), 2625-2629, 1990.

Selker, J., Design of interface shape for protective capillary barriers, Water Resour. Res., 33(1), 259-260, 1997. 
Steenhuis, T. S., J. -Y. Parlange, and K. -S. J. Kung, Comment on "The diversion capacity of capillary barriers, Water Resour. Res., 27(8), 2155-2156, 1991.

Stormont, J. C., The effect of constant anisotropy on capillary barrier performance, Water Resour. Res., 31(3), 783-785, 1995.

Su, G. W., J. T. Geller, K. Pruess and F. Wen, Experimental studies of water seepage and intermittent flow in unsaturated, rough-walled fractures, Water Resour. Res., 35(4), 1019-1037, 1999.

Tokunaga, T. K., and J. Wan, Water film flow along fracture surfaces of porous rock, Water Resour. Res., 33(6), 1287-1295, 1997.

Tokunaga, T. K., J. Wan and S. R. Sutton, Transient film flow on rough fracture surfaces, Water Resour. Res., 36(7), 1737-1746, 2000.

Tokunaga, T. K., and J. Wan, Surface-zone flow along unsaturated rock fractures, Water Resour. Res., 37(2), 287-296, 2001.

Wang, J. S. Y., and D. Elsworth, Permeability changes induced by excavation in fractured tuff, Proceedings of the American Rock Mechanics Association $37^{\text {th }}$ U.S. Rock Mechanics Symposium, 751-757, 1999.

Wang, J. S. Y., and T. N. Narasimhan, Unsaturated flow in fractured porous media, in Flow and Transport in Fractured Rock, edited by J. Bear, C. -F. Tsang and G. de Marsily, Academic Press, Inc., New York, pp. 325-391, 1993.

Wang, J. S. Y., R. C. Trautz, P. J. Cook, S. Finsterle, A. L. James, and J. Birkholzer, Field tests and model analyses of seepage into drift, J. Contam. Hydrol., 38(1999), 323-347, 1999. 
Walter, M. T., J. -S. Kim, T. S. Steenhuis, J. -Y. Parlange, A. Heilig, R. D. Braddock, J. S.

Selker, and J. Boll, Funneled flow mechanisms in a sloping layered soil: Laboratory investigation, Water Resour. Res., 36(4), 841-849, 2000.

Webb, S. W., Generalization of Ross' tilted capillary diversion formula for different two-phase characteristic curves, Water Resour. Res., 33(8), 1855-1859, 1997.

White, I., and M. J. Sully, Macroscopic and microscopic capillary length and time scales from field infiltration, Water Resour. Res., 23(8), 1514-1522, 1987. 
Table 1. Summary for niche seepage tests. Data have been adjusted for evaporation in the bottom half of table. On average, evaporation produces artificially high values of the capillary strength $\left(\alpha^{-1}\right)$ for the fractures.

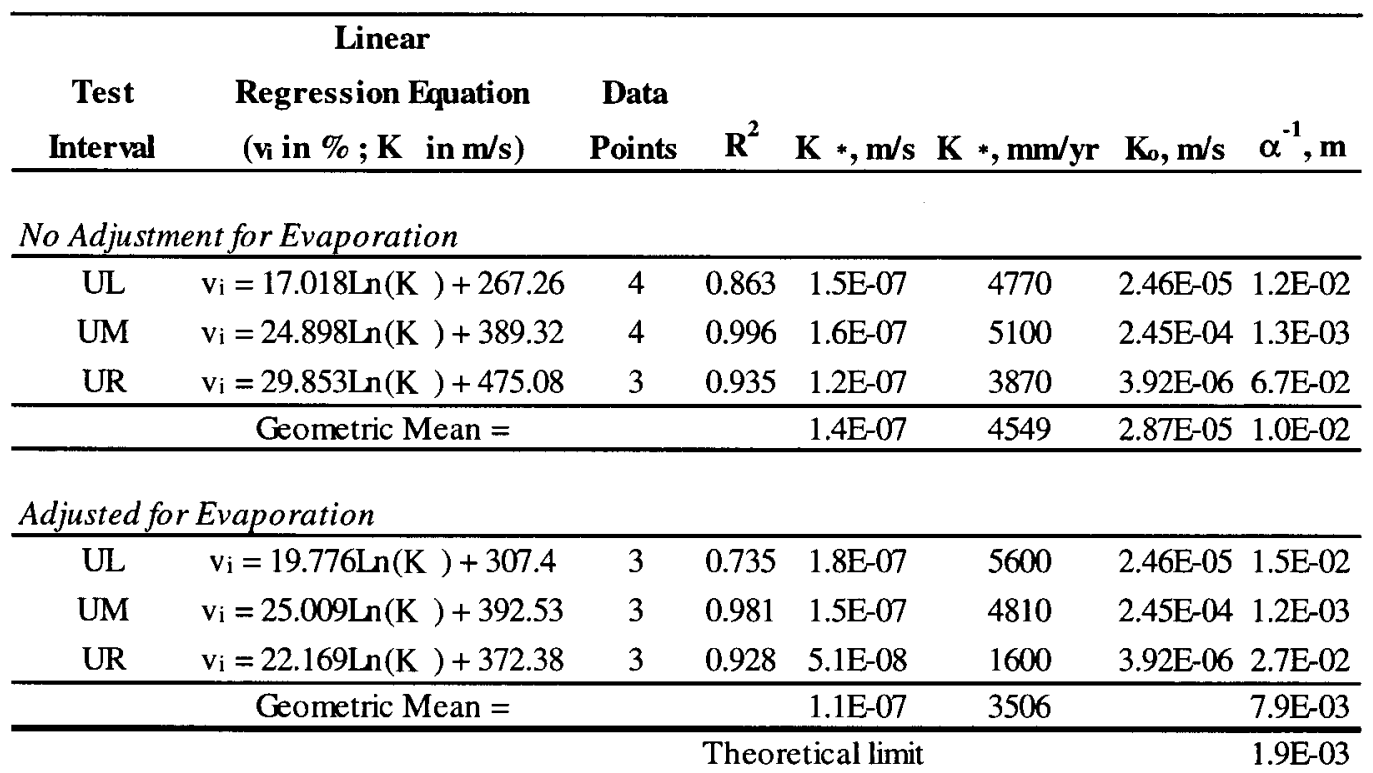




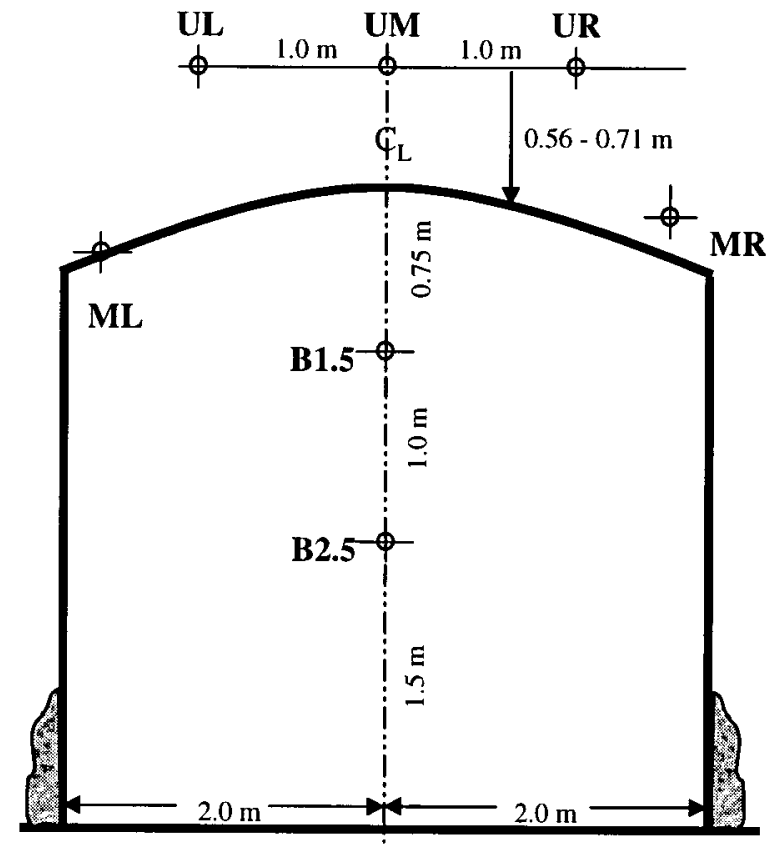

FIGURE 1. Configuration of boreholes and niche excavation. 


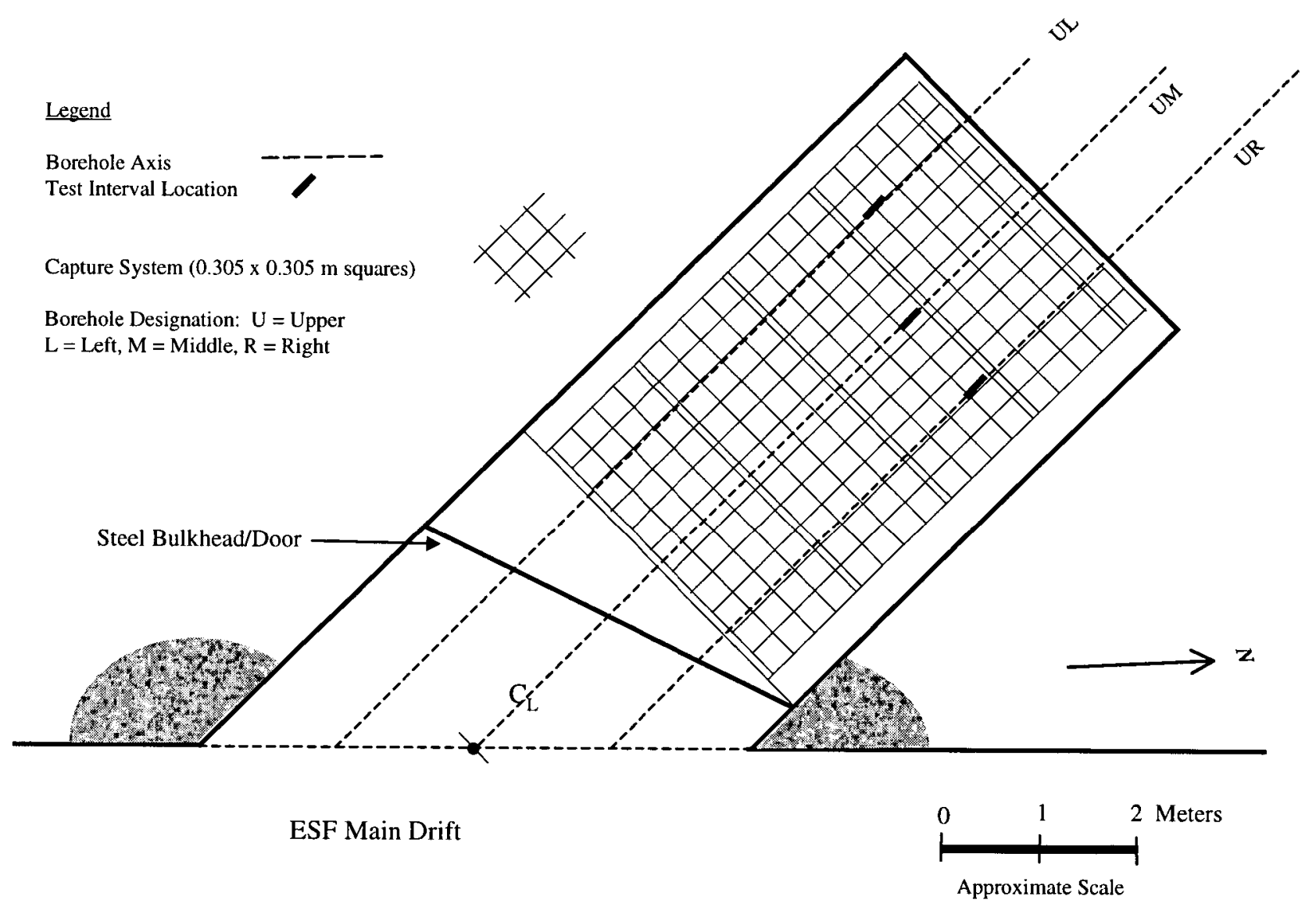

Figure 2. Plan view of niche showing intervals tested, location of boreholes UL, UM, and UR positioned above the opening and the location of the capture system within the niche. 


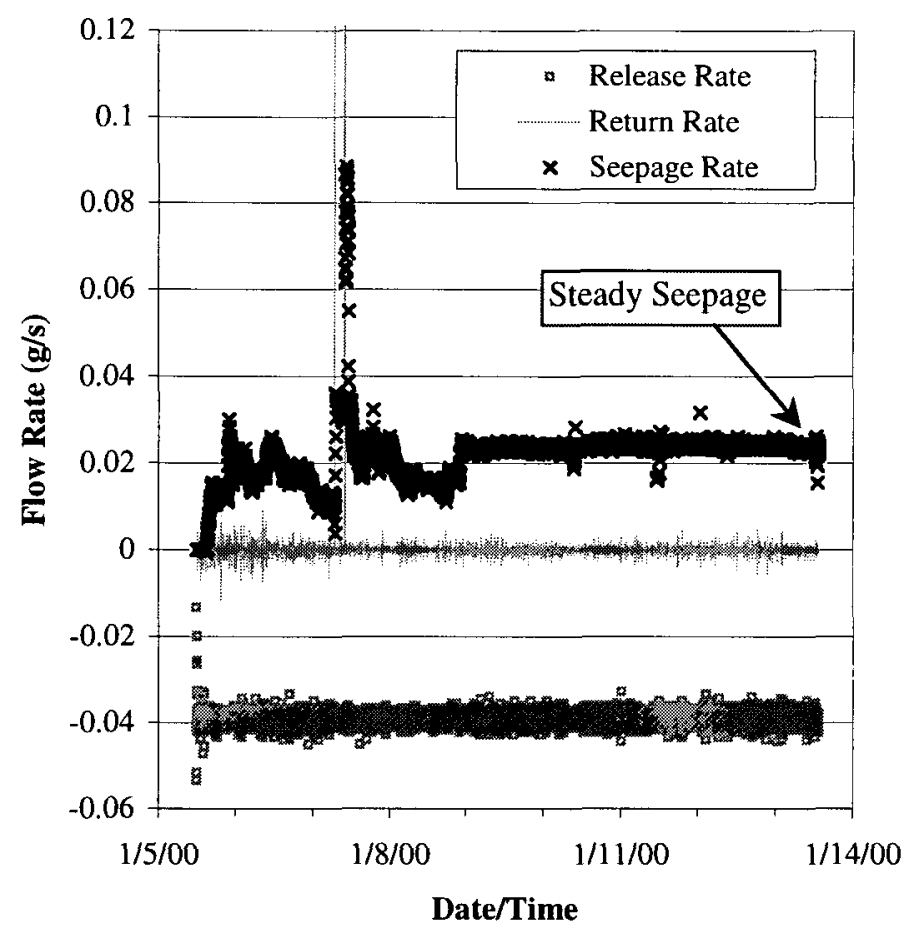

Figure 3. Stabilized flow rates observed during Test \#1 1-5-00 conducted on test interval UR. 


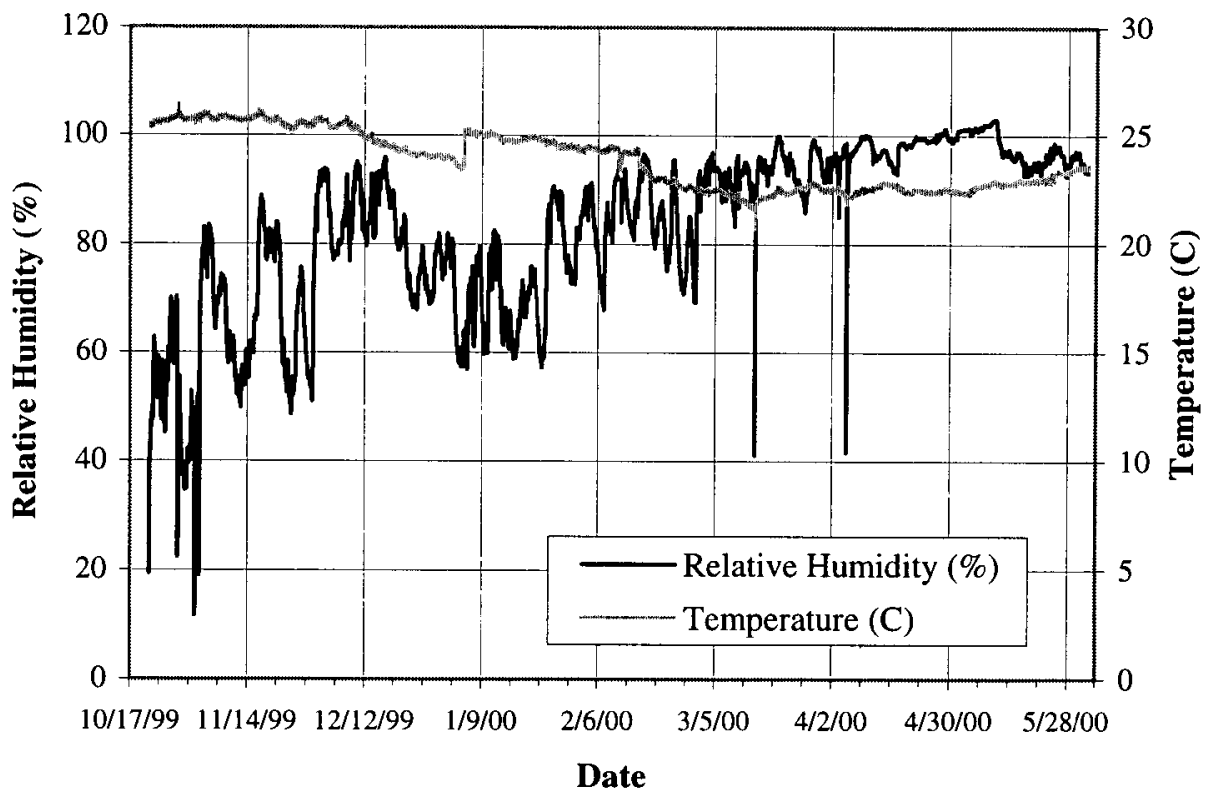

FIGURE 4. Air temperature and relative humidity inside the niche. 


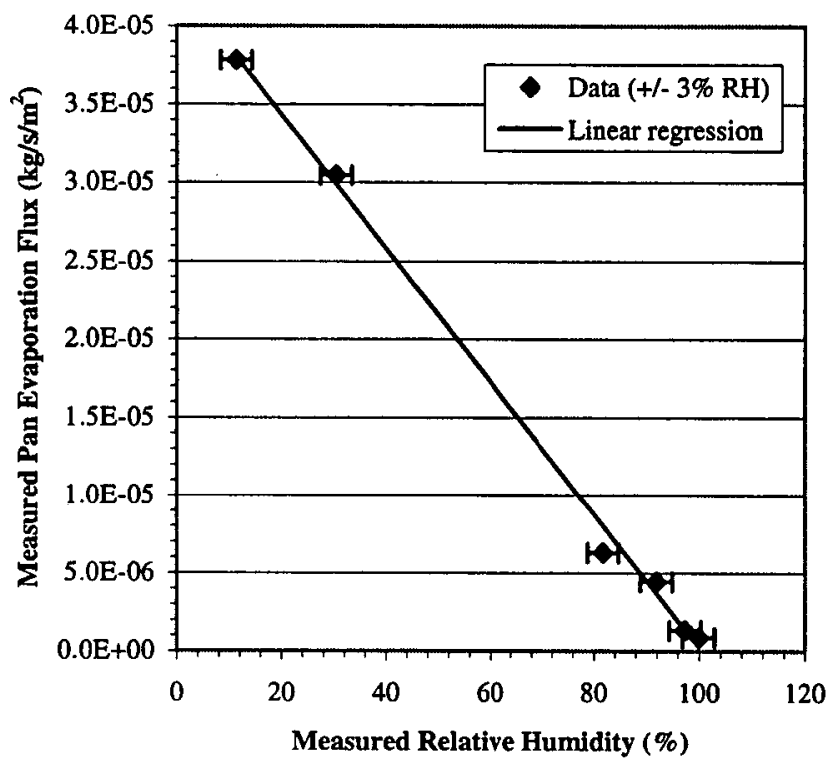

Figure 5. Linear relation between measured pan evaporation flux and relative humidity inside the niche 


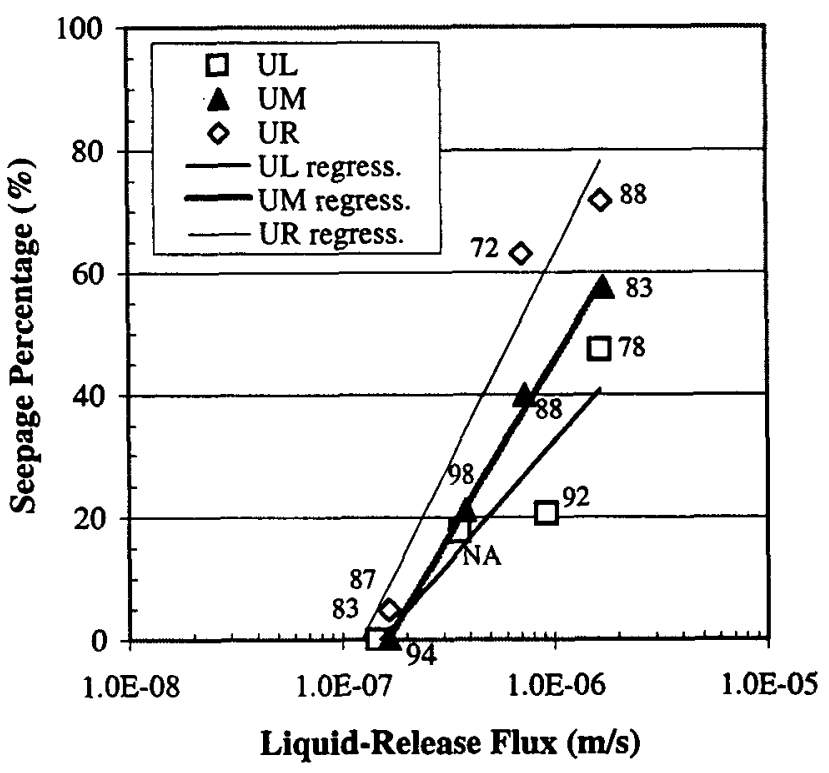

Figure 6a. Seepage percentage versus liquid-release fluxes.

Data are not adjusted for evaporation. Average relative humidity (\%) measured during test is shown adjacent to corresponding data point. $\mathrm{NA}=$ not available. 


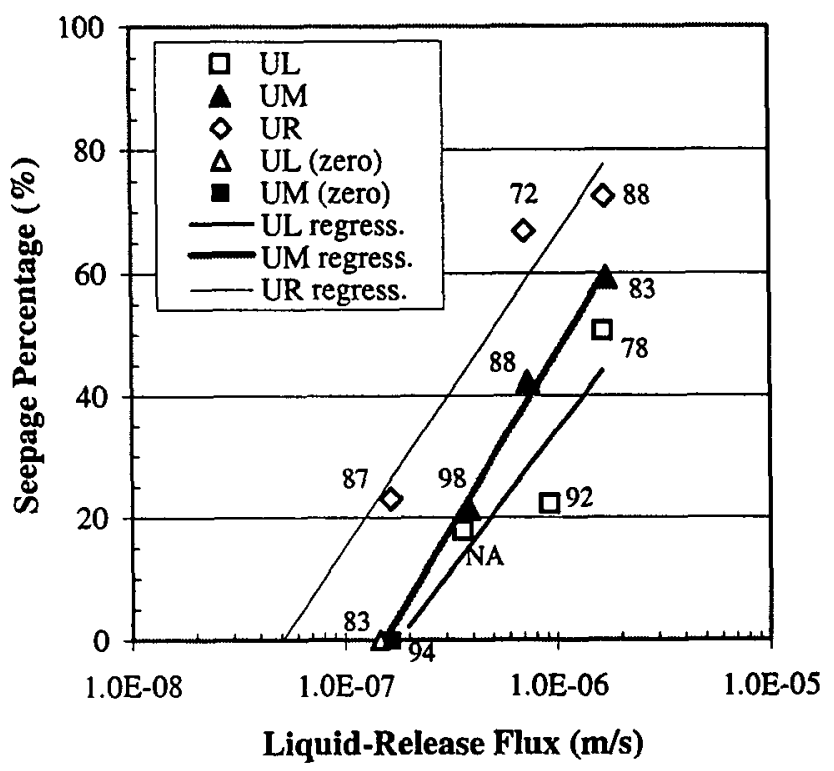

Figure 6b. Seepage percentage versus liquid-release fluxes.

Data are adjusted for evaporation. Average relative

humidity (\%) measured during test is shown adjacent to

corresponding data point. $\mathrm{NA}=$ not available. 


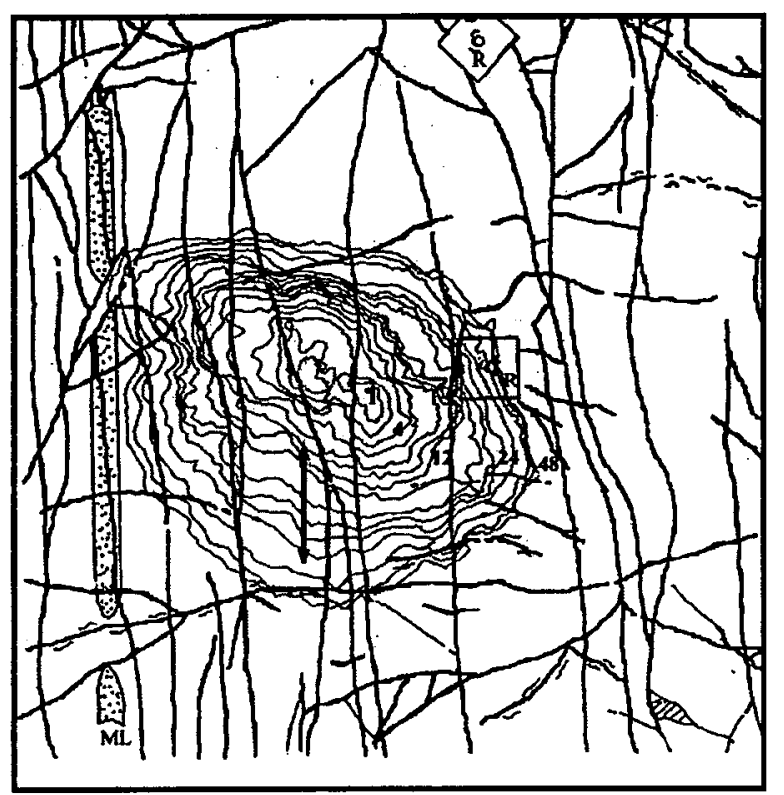

Figure 7. Contours show position of the wetting front as it spread across the niche ceiling. Numbers next to contours indicate time in hours it took for wetting front to reach this location. Double headed arrow shows the position of the $0.3 \mathrm{~m}$ long test interval UL where water was released $0.7 \mathrm{~m}$ above the drift. 
Figure 8. Seepage threshold fluxes for test intervals UM,

UL, and UR. Data above the line represent purely gravity dominated flow systems. Data plotting below the line have flow regimes influence by both gravity and capillary forces based on Laplace's Eq.

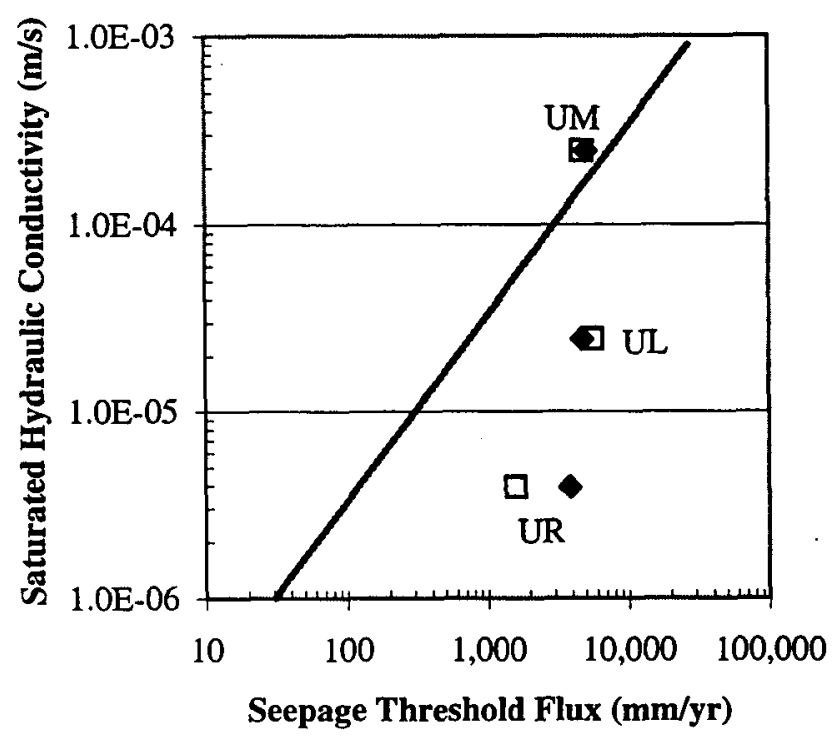

- Not Adjusted for Evaporation

口 Adjusted for Evaporation

$1 /$ alpha $=0.0019 \mathrm{~m}$ 


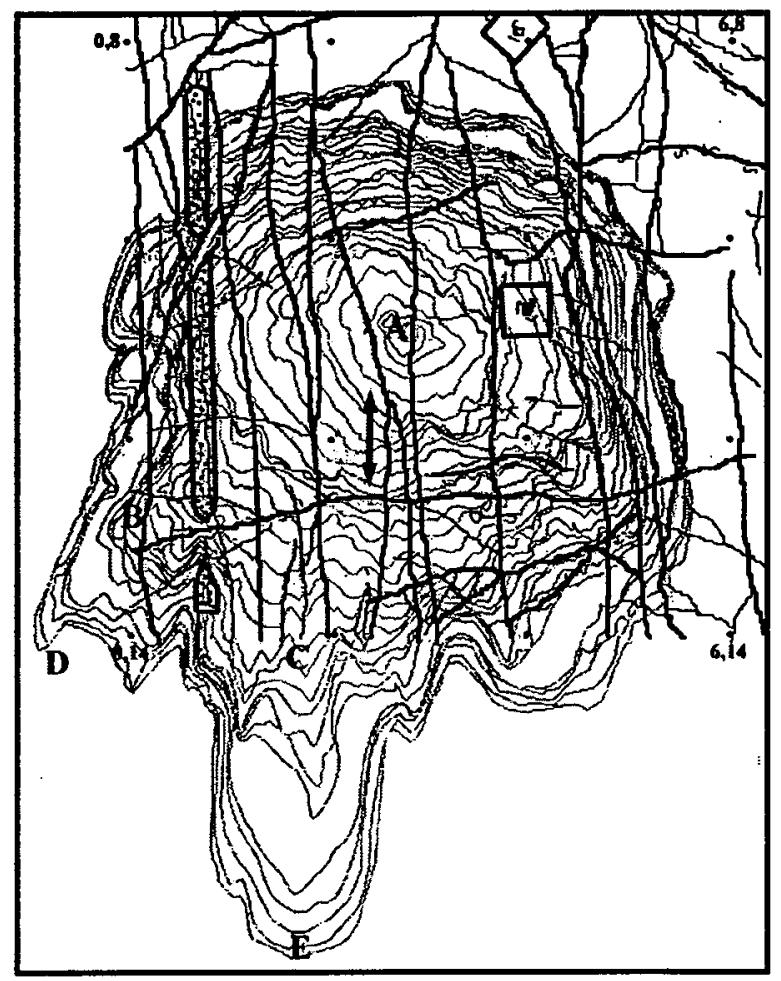

Figure 9. Lateral spreading of the wetting front across the niche ceiling from its point of origin (A) down the sidewall (B-D) and terminal wall (C-E) of the niche. Double-headed arrow shows the location of the overlying $0.3 \mathrm{~m}$ long liquid-release interval. 


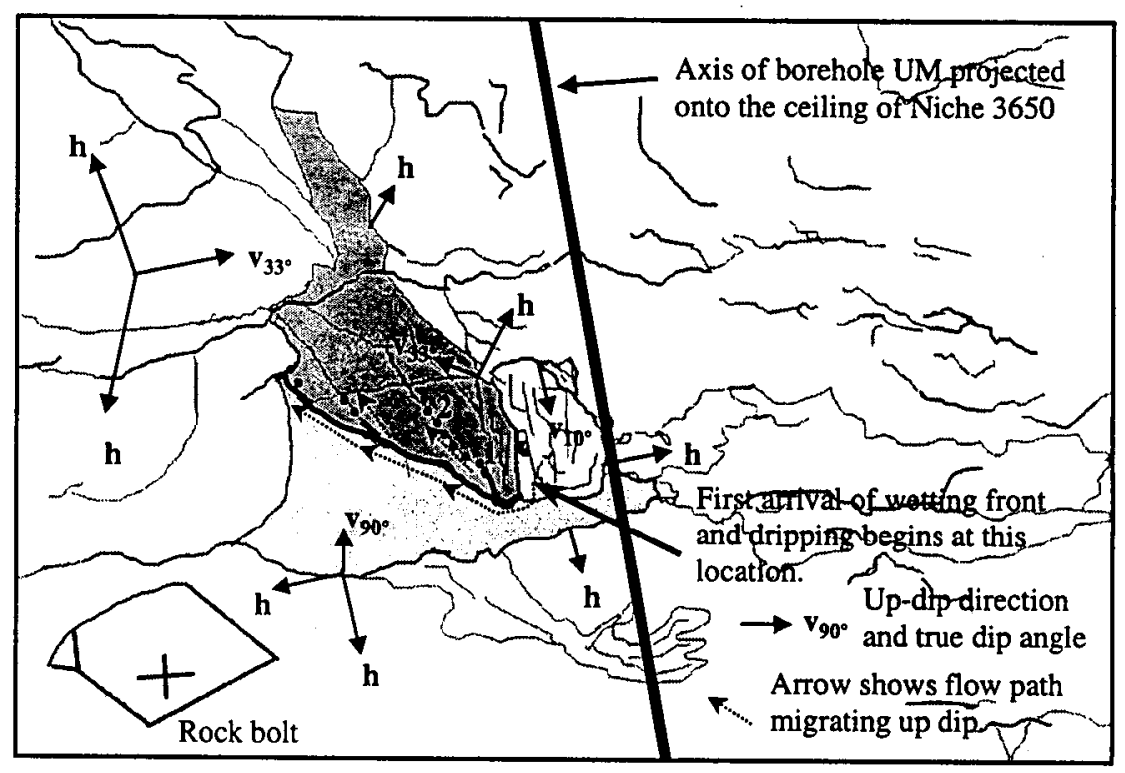

Figure 10. Position of the wetting front after arriving at the ceiling of Niche 3650 , showing influence of capillary barrier. 